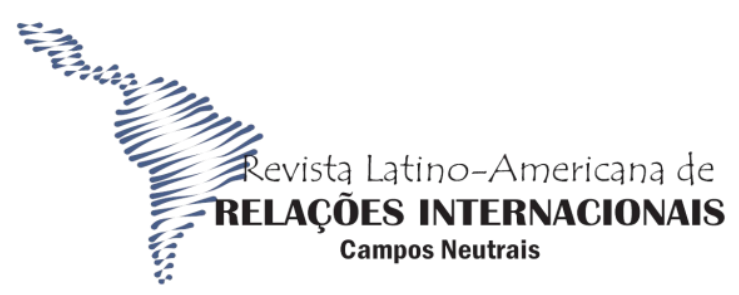

FURG

\title{
Ciclo de Palestras das Relações Internacionais da FURG na Pandemia de COVID-19
}

Cycle of Lectures of the International Relations Undergraduate Course at FURG in the COVID-19 Pandemic

Wagner Feloniuk

\section{Resumo}

A Atividade de Extensão Ciclo de Palestras do curso de Relações Internacionais da FURG atuou desde o início do curso, em 2015, buscando melhorar o ensino dos alunos e o contato das atividades acadêmicas com a comunidade de Santa Vitória do Palmar, onde o curso é sediado. A pandemia gerou a paralisação das aulas presenciais e, para continuar funcionando, a extensão precisou ser virtualizada. Este processo de fazer palestras virtualmente alcançou um resultado positivo e conseguiu dar visibilidade à extensão, que hoje tem um amplo número de presentes de todo o Brasil e até outros países. A trajetória é narrada neste trabalho.

Palavras-chave: Extensão. Pandemia de COVID-19. Ciclo de Palestras.

\begin{abstract}
The Extension Activity Cycle of Lectures of the International Relations Undergraduate Course at FURG has been active since the beginning of the course, in 2015, seeking to improve the learning of students and the contact of academic activities with the community of Santa Vitoria do Palmar, where the course is based. The pandemic stopped the on-campus classes, and to continue working, the extension had to be virtualized. This process of giving lectures virtually achieved a positive result and managed to give visibility to the extension, which today has a large number of participants from all over Brazil and even other countries. The trajectory is narrated in this work.
\end{abstract}

Keywords: Extension. COVID-19 Pandemic. Cycle of Lectures.

\section{Introdução}

O Ciclo de Palestras das Relações Internacionais é um Projeto de Extensão da Universidade Federal do Rio Grande (FURG) ${ }^{1}$ que vem sendo renovado ininterruptamente

\footnotetext{
${ }^{1}$ Atividade n. 1312.
} 
praticamente desde o início do curso das $\mathrm{RI}^{2}$. Este, por sua vez, é um curso relativamente recente, criado em 2015, e sediado na cidade de Santa Vitória do Palmar, no extremo sul do estado, no Campus da universidade estabelecido lá. São menos de 30 mil habitantes e cada oportunidade de trazer pesquisadores da área para palestrar aos alunos é importante.

Enquanto extensão, o Ciclo de Palestras tem algumas características decorrentes do contexto local. A primeira é servir a todos os professores do curso - os docentes podem utilizar a estrutura para seus eventos, como palestras, seminários, oficinas. Não há obrigatoriedade, é uma forma de facilitar qualquer organização, permitindo que todo o aspecto burocrático seja feito apenas uma vez, ao final de cada ano.

O segundo aspecto relevante é a participação dos graduandos do curso. Há uma interação alta, os alunos podem trazer demandas e sugestões de palestrantes, apoiar a organização, enfim, fazer parte efetivamente do projeto, sejam bolsistas ou não. A proximidade é uma decorrência de um corpo docente pequeno e de uma cidade que faz com que as interações entre alunos e professores sejam constantes.

O Ciclo existiu e funcionou dentro das capacidades e disponibilidades, initerruptamente, durante todo o período anterior à pandemia, com diferentes professores atuando como organizadores ao longo dos anos. Foi comum que eventos particularmente grandes fossem separados, e convites individuais a palestrantes fossem organizados com ele.

Imagem 1 - Projeto Gráfico do Ciclo das RI, elaboração dos discentes do curso

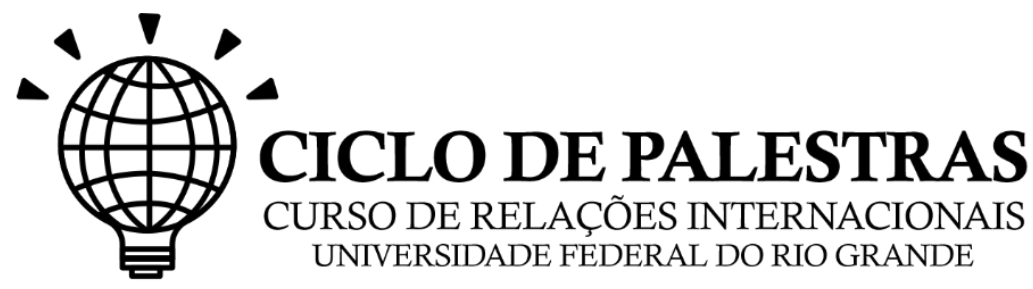

Fonte: Curso de Relações Internacionais.

\section{A Pandemia de COVID-19}

\footnotetext{
${ }^{2}$ Site do Curso de Relações Internacionais da FURG, com dados sobre a história e, também, os eventos: $<$ https://ri.furg.br/.>.
} 


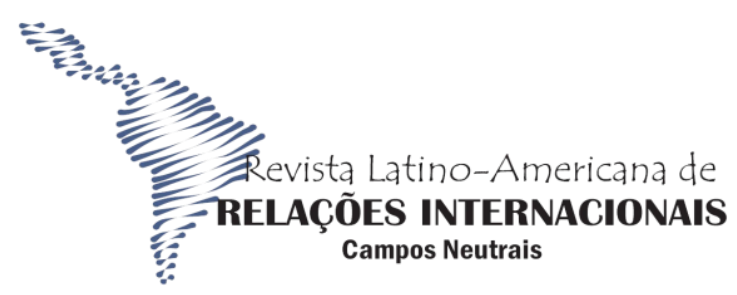

Antes de 2020, predominaram as atividades presenciais. Eram professores que se deslocavam até Santa Vitória do Palmar para palestrar aos alunos. Foram diversas as atividades feitas nesse modelo, que cumpria bem os seus objetivos.

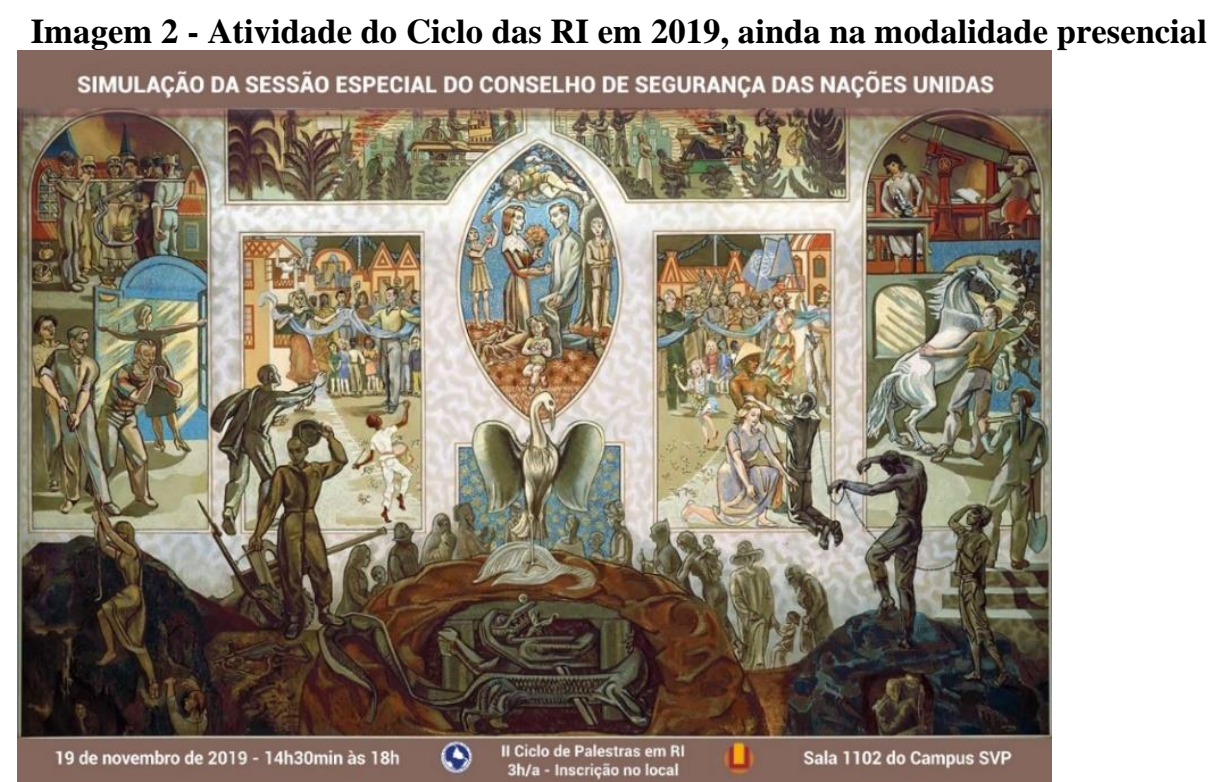

Fonte: Curso de Relações Internacionais.

No início do ano de 2020, antes de a pandemia atingir o Brasil, houve uma primeira atividade, presencial. Ao chegar março, as atividades presenciais foram interrompidas, conforme as instruções da universidade - normas próximas de tantas que estavam sendo aplicadas na maior parte das instituições de ensino superior do país. O contexto levou a uma interrupção temporária. Foi o momento de adaptação institucional e construção de soluções que chegaria, tempos depois, ao atual modelo híbrido e, ao menos no curso de RI/FURG, de predominância de atividades feitas virtualmente. O Ciclo não fora pensado para um momento de pandemia.

Surgiu, então, a ideia de reformular o projeto. Trazê-lo ao momento vivido de maneira intensa, inclusive como forma de manter os alunos unidos em um período inicial de incertezas sobre as atividades e preocupação com o desligamento deles de seus estudos.

\begin{tabular}{|c|c|c|c|c|}
\hline $\begin{array}{l}\text { CAMPOS NEUTRAIS } \\
\text { REVISTA LATINO-AMERICANA DE RELAÇÕES INTERNACIONAIS }\end{array}$ & Rio Grande & v. 3, n. 2 & p. $95-108$ & Maio-Ago 2021 \\
\hline
\end{tabular}


Assim, com importante apoio dos alunos, foi criado um modelo novo, no qual o Ciclo seria inteiramente feito pela internet, com uso das estruturas oferecidas gratuitamente em plataformas e pela universidade. Este seria o modelo que levaria o Ciclo a um momento positivo e intenso de atividades, à participação de alunos de todo o Rio Grande do Sul - e do restante do país - e à possibilidade de participação de palestrantes espalhados pelo Brasil, criando uma integração intensa para um curso sediado no campus mais ao sul do território nacional e transformando a adversidade em um momento positivo e que seria reconhecido pela comunidade ${ }^{3}$.

\section{Ciclo durante a Pandemia}

A primeira atividade do Ciclo após a pandemia foi em abril de 2020. Ao longo do ano, então, foram realizados um total de 32 atividades (33 se contada a palestra em auditório, anterior à interrupção). Não é possível saber exatamente a quantidade de pessoas presentes, pois a inscrição era facultativa, apenas aos interessados em certificação. A quantidade de certificados solicitados ao final do ano, no entanto, é conhecida. Foram 1.265. É uma quantidade relevante para um curso que possui pouco mais de cem alunos.

\footnotetext{
${ }^{3}$ Notícia inserida no site da Universidade: "Ciclo de Palestras no Campus FURG Santa Vitória do Palmar tem ampla participação do público". Disponível em: <https://www.furg.br/noticias/noticias-svp/ciclo-depalestras-no-campus-furg-santa-vitoria-do-palmar-tem-ampla-participacao-do-publico>. Acesso em: 29 mar. 2021.
} 

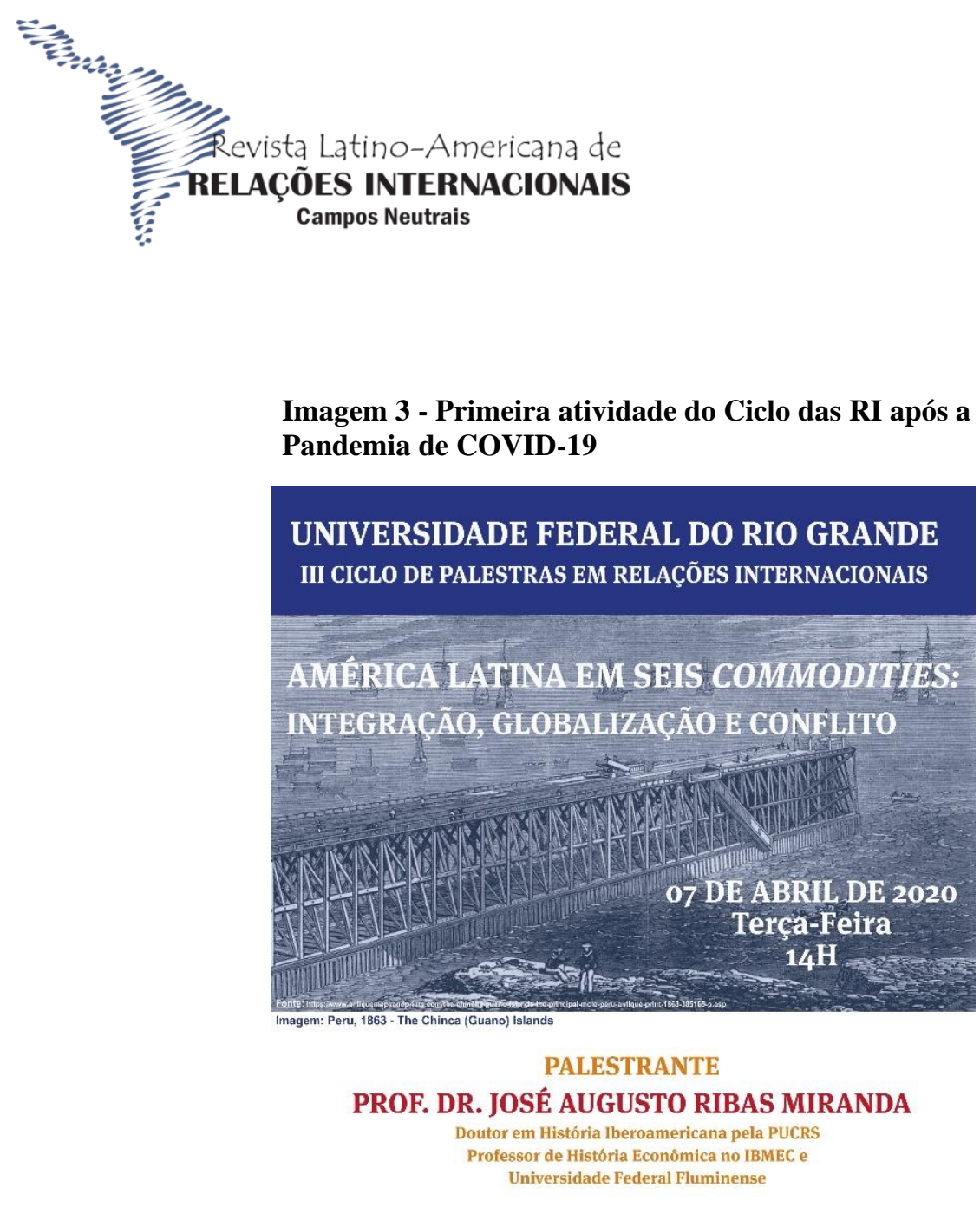

LOCAL: Palestra pela Plataforma MConf (via Navegadores) Acesso: https://conferenciaweh.rnp.br/wehconf/fernando-fernando-comiran
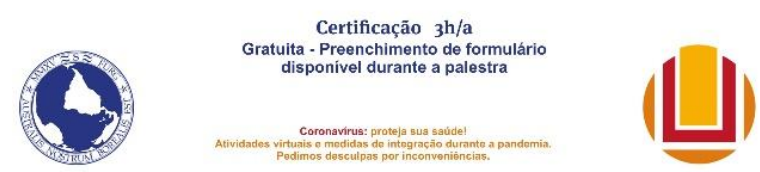

Fonte: Curso de Relações Internacionais.

Como comparação, durante 2019, com atividades presenciais, a prestação de contas havia chegado aos 383 pedidos de certificação. O total de atividades fora 11. Era um resultado bom, fruto da disposição de professores em organizar e também em se deslocar até a cidade.

A Pandemia de COVID-19 trouxe, em meio a tantas dificuldades, um momento de adaptação para a extensão. Sua realização modificou completamente o projeto, possivelmente com impactos permanentes. A extensão virtual permitiu trazer palestrantes do Brasil e, em 2021, de fora dele. Pessoas que normalmente teriam dificuldade grande para chegar ao campus tiveram contato com os alunos e o curso fez ligações proveitosas com

\begin{tabular}{|c|c|c|c|c|}
\hline $\begin{array}{c}\text { CAMPOS NEUTRAIS } \\
\text { REVISTA LATINO-AMERICANA DE RELAÇÕES INTERNACIONAIS }\end{array}$ & Rio Grande & v. 3 , n. 2 & p. $95-108$ & Maio-Ago 2021 \\
\hline
\end{tabular}


outros locais e instituições. É provável que em um momento pós-pandemia, as atividades presenciais vão conviver com palestras à distância, permitindo que a normalidade venha acompanhada dos aspectos positivos trazidos por essa introdução não planejada ao ambiente virtual. Ao todo, mais de sessenta eventos científicos foram organizados até o mês de novembro de 2021.

Os eventos buscaram a amplitude de temas. Também houve a busca por parcerias com outras instituições e órgãos da própria universidade. Essas possibilidades foram utilizadas para incrementar o público e incentivar o contato acadêmico da extensão em si, assim como dos alunos.

Imagem 4 - Evento com maior número de presentes (cerca de 150)

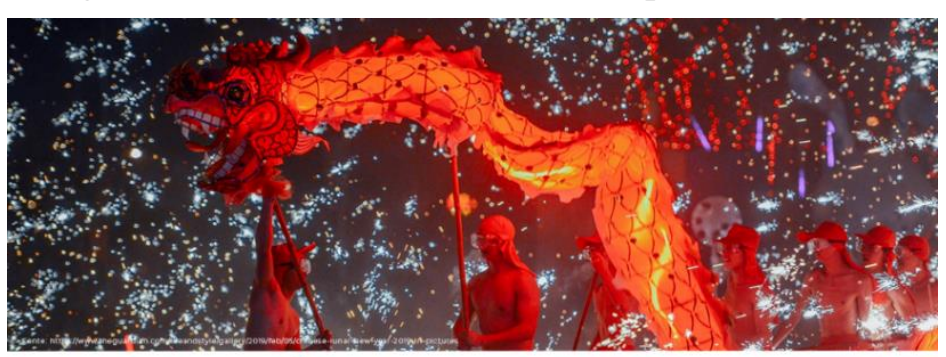

太 PULÍTICA EXTERNA DA CHINA PARA 太LÉm DA NOVA RDTA DA SEDA: atores, objetivos e impactos no Sul Global
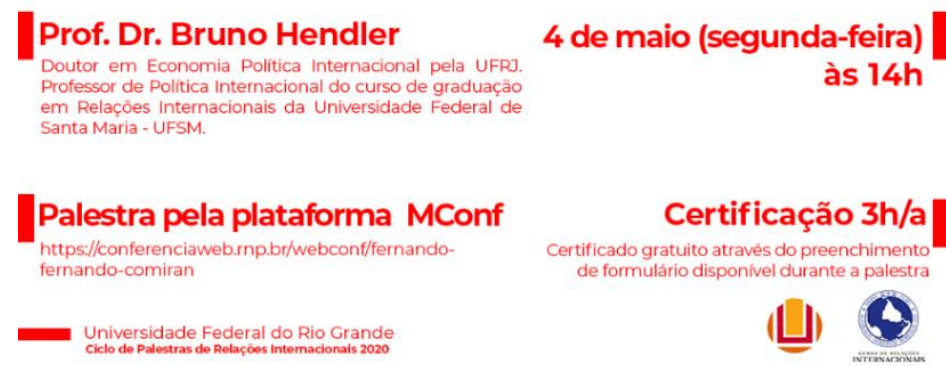

Fonte: Curso de Relações Internacionais.

\section{Estrutura durante a Pandemia}

Após narrar os acontecimentos ao longo do ano, vale citar a estrutura da extensão ao longo de 2020 e 2021, para tentar contribuir com outras atividades semelhantes no futuro. O Ciclo das RI tinha as seguintes características:

a) docentes poderiam organizar eventos dentro do Ciclo, muitas vezes por sugestões e demandas trazidas pelos alunos. Essas atividades ocorreram com professores do curso, de outros cursos, em parcerias diversas e também com setores da Universidade. A ideia era 


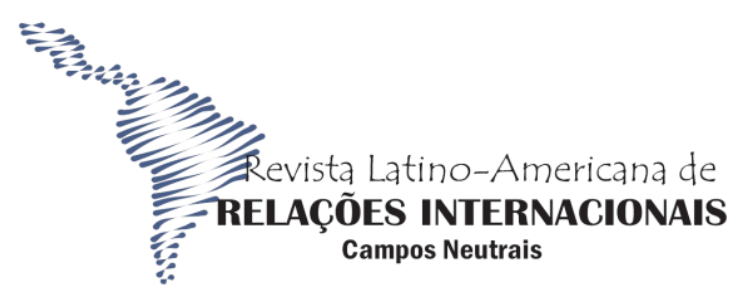

incluir o máximo de iniciativas interessantes e que contribuíssem com a formação dos alunos;

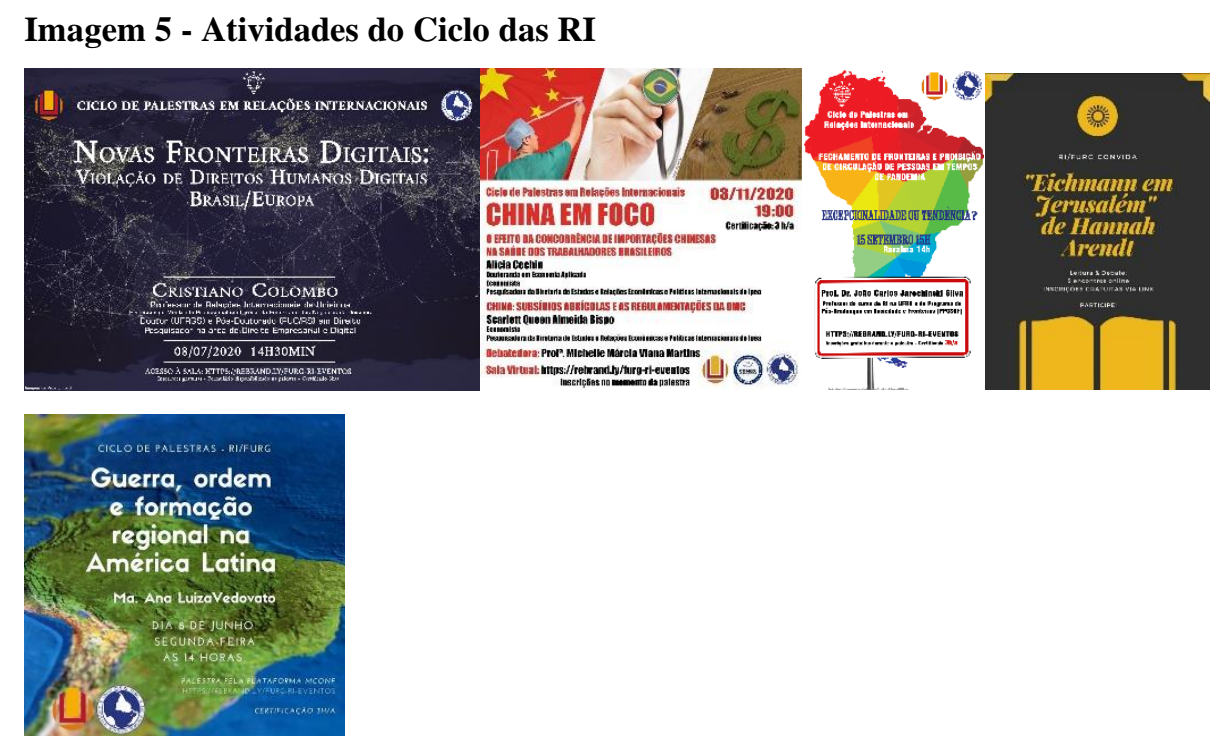

Fonte: Curso de Relações Internacionais.

b) o primeiro passo era discutir a data e horário planejado, para evitar que duas atividades do curso (desta ou de outras iniciativas) ocorressem concomitantemente. Também houve a busca por momentos no qual houvesse poucas disciplinas e, em um turno de um dia em específico, não havia disciplinas no curso, o que fez ser um horário preferencial;

c) havia uma ideia de flexibilidade nas atividades do Ciclo. Palestras, oficinas, uma aula magna por ano, workshops, eram as atividades padrão. Mas outros acontecimentos foram somados. Assim, grupos de leitura, simulações de tribunais internacionais, mesas redondas e outras iniciativas foram sendo agregadas durante a execução da extensão. Só era importante haver delineada a ideia de extensão e o caráter científico. Portanto, o ingresso era livre a qualquer membro do campus e, genericamente, da comunidade ${ }^{4}$;

\footnotetext{
${ }^{4}$ Conforme o art. 20 do Regimento de Horas Complementares, art. 38 do Regimento da Universidade e, genericamente, a Lei de Diretrizes e Bases da Educação.
}

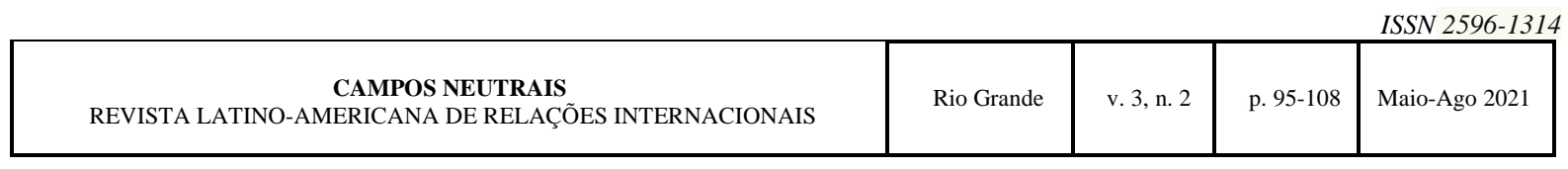


Ciclo de Palestras das Relações Internacionais da FURG na Pandemia de COVID-19

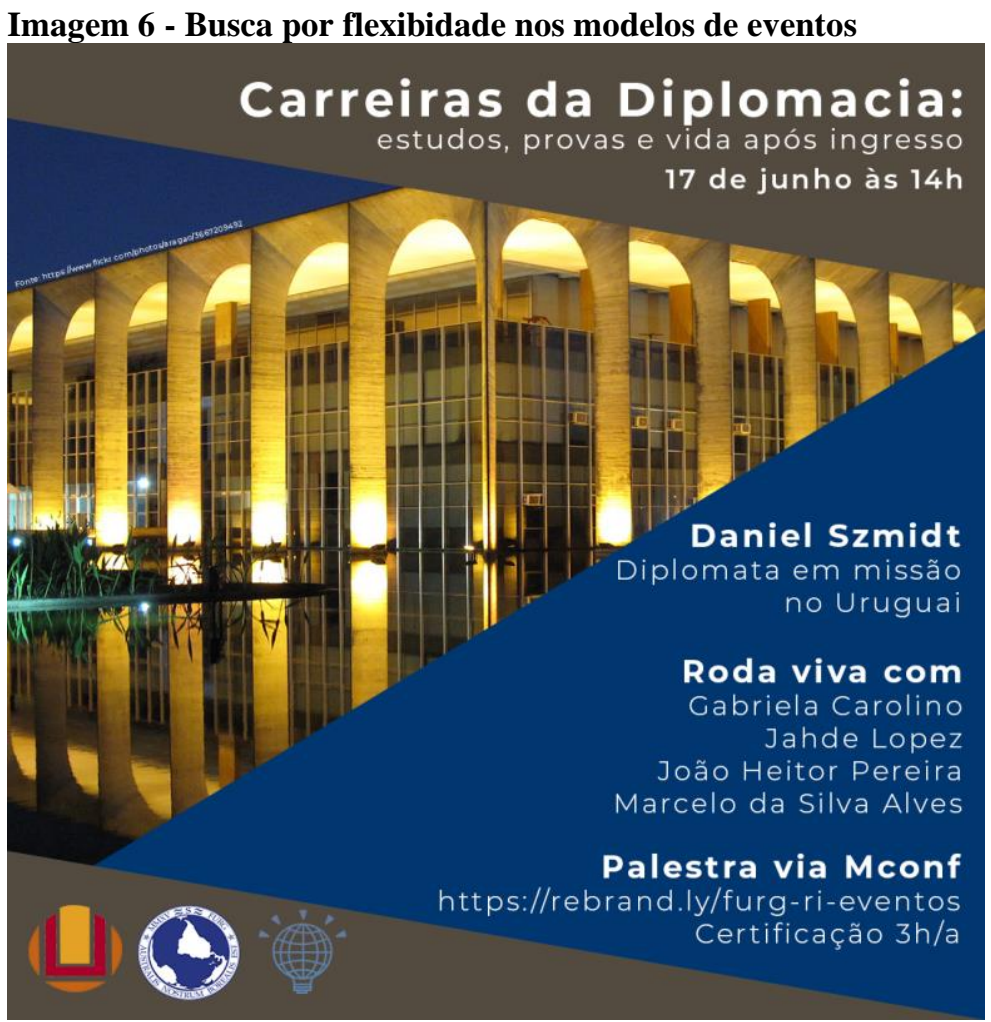

Fonte: Curso de Relações Internacionais.

d) material de divulgação: marcado o dia, era feito o material de divulgação. Normalmente, um cartaz. Houve um leque grande de adaptações feitas, especialmente por sugestões dos alunos. Os modos de atingir pessoas nas redes sociais variam bastante, então tamanhos e locais de inserção desses materiais, especialmente nas redes sociais, dependeram bastante do auxílio e conhecimento dos discentes. Este cartaz era elaborado pelos organizadores ou alunos. A ideia também era de flexibilidade, os requisitos estavam ligados apenas a ter o meio de acesso, dia, horário e dados da palestra. A maior parte deles também trazia textos padrões sobre ser parte do Ciclo (e uso de logos), gratuidade, certificação gratuita a membros externos. Eventualmente, em função da conveniência, houve cartazes com diferentes fusos horários, fotos de palestrantes, explicações sobre a atividade; 
- nas redes sociais do curso e em outras redes que os discentes tinham acesso, como grupos regionais de estudantes, procurando atingir o máximo de graduandos interessados;

- e, em eventos de interesse institucional, no Site da Universidade, por meio de pedido ao setor de comunicação da instituição;

f) inscrições: foi decidido não ter inscrições prévias. A inscrição era feita durante a atividade, oferecida por meio de formulário, cujo preenchimento era opcional. Aqueles que preenchiam, receberiam depois o certificado de atividades. O objetivo foi fazer um formulário muito curto, com estrutura sempre parecida, que facilitasse o processo de inscrição formal. Ela era gratuita e não havia nenhum tipo de restrição, nem a estrangeiros;

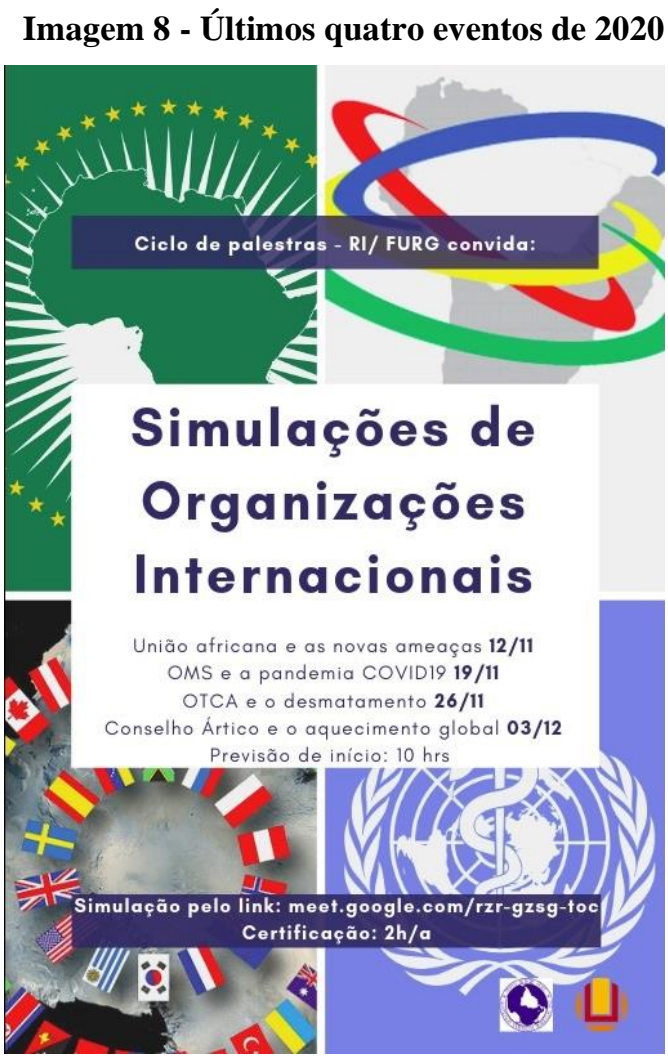

Fonte: Curso de Relações Internacionais.

g) antes do evento ocorrer, pequenas atividades prévias eram realizadas. Por exemplo, alguns palestrantes pediam para conhecer o ambiente no qual palestrariam. O link do cartaz (que era fixo e, na maior parte do tempo, apontava para o Site do Curso) era configurado para apontar para o local de efetiva transmissão. Cerca de quinze minutos antes, a sala era aberta e as pessoas ingressavam. Havia alguma interação e avisos do curso durante este momento;

h) em si, o evento era feito em uma sala virtual. Em algumas oportunidades, todos os ouvintes ficavam na sala com os palestrantes. Em outras, os palestrantes ficavam em uma 


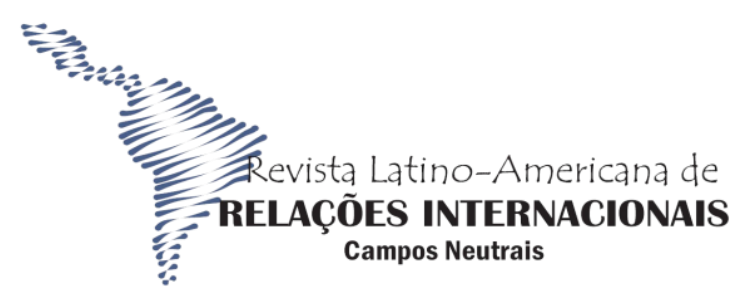

FURG

sala e a transmissão era feita para um popular site de vídeos da internet, o que permitia que um número indefinido de pessoas acompanhasse o evento. Essa transmissão não era sempre tranquila, havendo mais facilidade técnica quando os palestrantes e alunos ficam na mesma sala - tanto para interagir, quanto por diversas dificuldades de perda de qualidade e interrupções durante transmissões;

i) o evento costumava ser estruturado com forte semelhança a eventos científicos presenciais na respectiva modalidade (mesa redonda, workshop, palestra). Uma introdução às atividades do dia e biografia do palestrante era feita por um professor organizador. Após, o palestrante tomava a palavra e, na maior parte das vezes, não interagia frequentemente com os presentes durante a fala. No final, se iniciava a parte do diálogo, que era feita por debatedores convidados (se houvesse), organizadores e ouvintes. Ainda que todos tivessem acesso a áudio e vídeo na parte final, era normal que os alunos preferissem utilizar o chat, e docentes, a voz. O encerramento era feito com agradecimentos, avisos sobre outros eventos e, não raro, um final de transmissão feita com as palavras de conclusão do convidado;

i) após o evento: os formulários são processados, todos são tabelados com os dados que mais tarde serão utilizados para pedir certificados. Em geral, faziam-se contatos com os palestrantes para agradecer pela participação. Era importante deixar organizada essa "burocracia" logo após o evento, pois a grande quantidade de atividades geraria um risco relevante de desorganização se fosse feito de outra forma;

j) prestação de contas: apenas uma vez por Ciclo, normalmente no início do ano seguinte, é feita a prestação de contas com todos os ouvintes, organizadores e palestrantes, que então recebem seus certificados, elaborados pela universidade, e retirados virtualmente após um aviso por $e$-mail. 
Ciclo de Palestras das Relações Internacionais da FURG na Pandemia de COVID-19

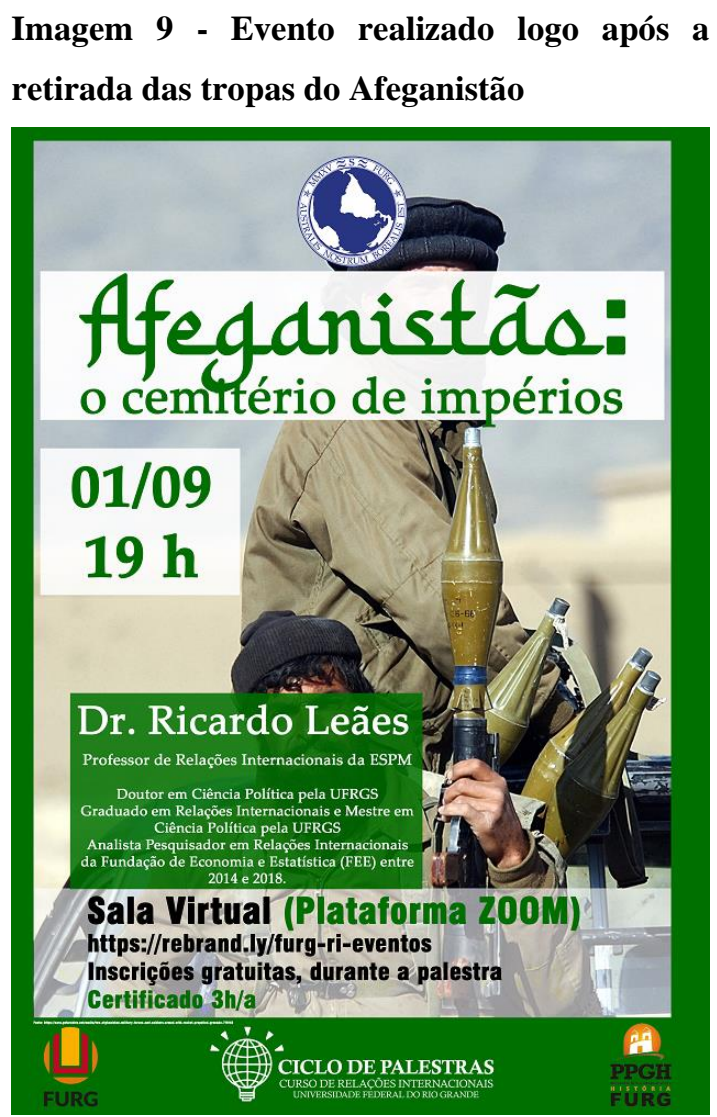

Fonte: Curso de Relações Internacionais.

Diversos eventos tiveram estrutura própria, então pequenas alterações estiveram presentes. Algumas vezes, foram séries de atividades, e um único cartaz foi elaborado com todas as datas. Outros eventos eram com grupos, então havia um número menor de presentes, e a estrutura da atividade era adequada às necessidades e objetivos. Também houve uma situação de mesa redonda, na qual alunos participaram perguntando e interagindo com o palestrante, um profissional atuando em uma das carreiras públicas desejadas por alunos de Relações Internacionais. 

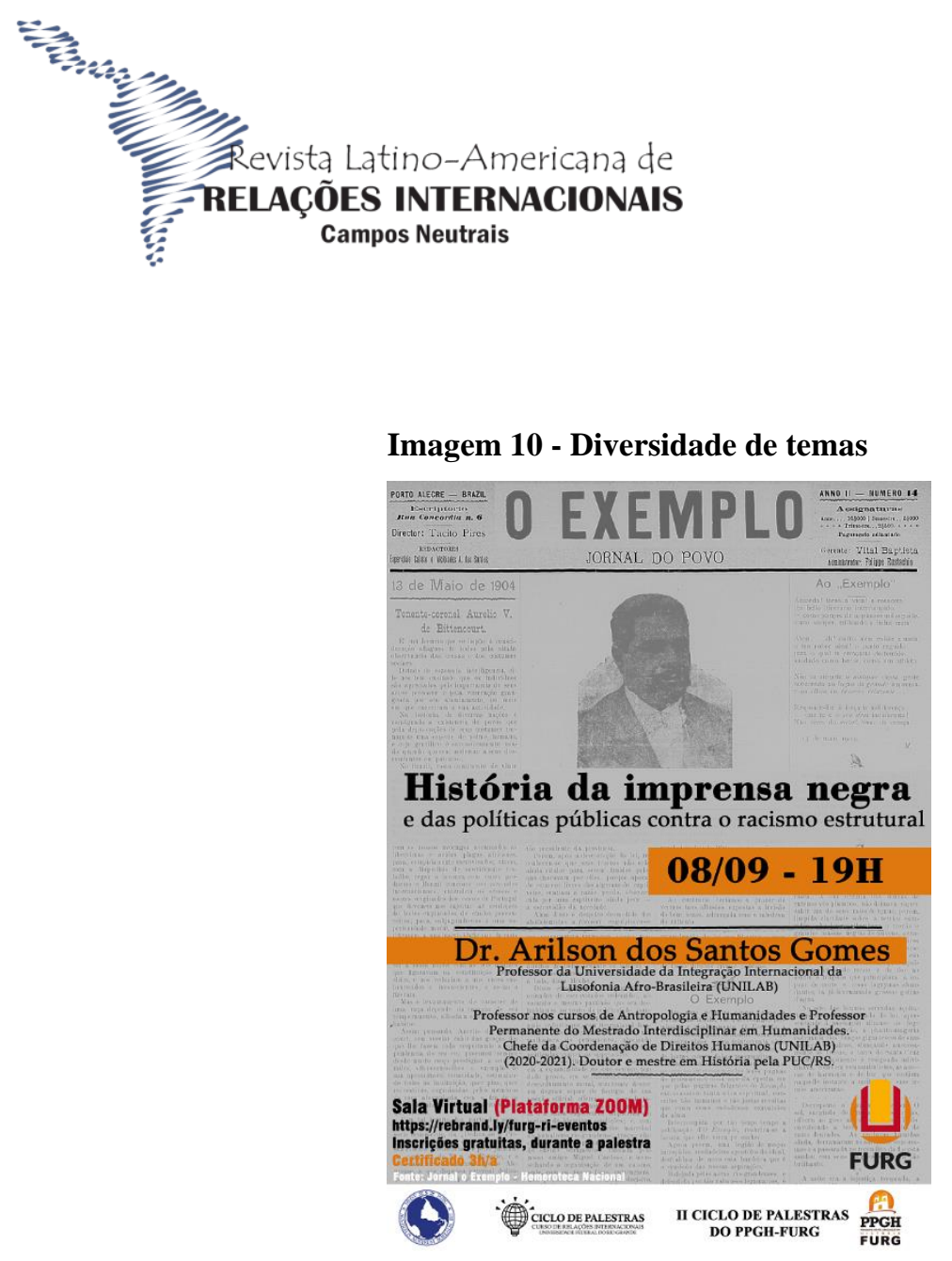

Fonte: Curso de Relações Internacionais.

\section{Considerações Finais}

O Ciclo de Palestras das Relações Internacionais tinha a possibilidade de se adaptar ao ambiente virtual. Ao utilizar essa oportunidade, foi possível fazer ele crescer de uma maneira não imaginada anteriormente, aumentando suas atividades, a presença de alunos, a diversidade de palestrantes, ter um alcance que superava o próprio curso. A extensão também pôde ser utilizada como um fator de união do curso, um momento de encontro com alunos que estavam temporariamente sem aulas, e à entrega de um ensino de mais qualidade e mais interação com a comunidade da área. A experiência virtual não fora planejada, mas trouxe alguns elementos que permanecerão, um ponto positivo em um momento de dificuldades tão graves.

ISSN 2596-1314 


\section{Referências}

BRASIL. Diretrizes e Bases da Educação Nacional. Rio Grande. Rio Grande: Furg, 2009.

BRASIL. Universidade Federal do Rio Grande. Ciclo de Palestras no Campus Furg Santa Vitória do Palmar tem ampla participação do público. Disponível em: $<$ https://www.furg.br/noticias/noticias-svp/ciclo-de-palestras-no-campus-furg-santavitoria-do-palmar-tem-ampla-participacao-do-publico>. Acesso em: 29 out. 2021.

BRASIL. Universidade Federal do Rio Grande. Projeto n. 1312 - III Ciclo de Palestras de Relações Internacionais.

BRASIL. Universidade Federal do Rio Grande. Regimento Geral da Universidade Federal do Rio Grande. Rio Grande: Furg, 2009.

BRASIL. Universidade Federal do Rio Grande. Regulamento de Atividades Complementares do Curso de Relações Internacionais. Deliberação n. 01/2020. Rio Grande. Rio Grande: Furg, 2009.

BRASIL. Universidade Federal do Rio Grande. Site do Curso de Relações

Internacionais da FURG. Disponível em: <https://ri.furg.br/>. Acesso em: 29 out. 2021.

DOLINGER, Jacob. Direito internacional privado. Rio de Janeiro: Renovar, 2002.

REZEK, Francisco. Direito internacional público: curso elementar. São Paulo: Saraiva, 2014 